\title{
Amyotrophic Lateral Sclerosis 2-Deficiency Leads to Neuronal Degeneration in Amyotrophic Lateral Sclerosis through Altered AMPA Receptor Trafficking
}

\author{
Chen Lai, ${ }^{1}$ Chengsong Xie, ${ }^{1}$ Stefanie G. McCormack, ${ }^{2}$ Hsueh-Cheng Chiang, ${ }^{3}$ Marta K. Michalak,,${ }^{2,7}$ Xian Lin, ${ }^{1}$ \\ Jayanth Chandran, ${ }^{1}$ Hoon Shim, ${ }^{1}$ Mika Shimoji, ${ }^{1}$ Mark R. Cookson, ${ }^{1}$ Richard L. Huganir, ${ }^{4,6}$ Jeffrey D. Rothstein, ${ }^{5}$ \\ Donald L. Price, ${ }^{3,4,5}$ Philip C. Wong, ${ }^{3,4}$ Lee J. Martin, ${ }^{3,4}$ J. Julius Zhu, ${ }^{2}$ and Huaibin Cai ${ }^{1}$ \\ ${ }^{1}$ Laboratory of Neurogenetics, National Institute on Aging, National Institutes of Health, Bethesda, Maryland 20892, ${ }^{2}$ Department of Pharmacology and \\ Neuroscience Graduate Program, University of Virginia School of Medicine, Charlottesville, Virginia 22908, Departments of ${ }^{3}$ Pathology, ${ }^{4}$ Neuroscience, and \\ ${ }^{5}$ Neurology, and ${ }^{6}$ Howard Hughes Medical Institute, The Johns Hopkins University School of Medicine, Baltimore, Maryland 21205, and 7 Biotechnology \\ Graduate Program, Technical University of Łódź, 90-924 Łódź, Poland
}

Amyotrophic lateral sclerosis (ALS), the most common adult-onset motor neuron disease is caused by a selective loss of motor neurons. One form of juvenile onset autosomal recessive ALS (ALS2) has been linked to the loss of function of the ALS2 gene. The pathogenic mechanism of ALS2-deficiency, however, remains unclear. To further understand the function of alsin that is encoded by the full-length ALS2 gene, we screened proteins interacting with alsin. Here, we report that alsin interacted with glutamate receptor interacting protein 1 (GRIP1) both in vitro and in vivo, and colocalized with GRIP1 in neurons. In support of the physiological interaction between alsin and GRIP1, the subcellular distribution of GRIP1 was altered in $A L S 2^{-/-}$spinal motor neurons, which correlates with a significant reduction of AMPA-type glutamate receptor subunit 2 (GluR2) at the synaptic/cell surface of $A L S 2^{-/-}$neurons. The decrease of calciumimpermeable GluR2-containing AMPA receptors at the cell/synaptic surface rendered $A L S 2^{-/-}$neurons more susceptible to glutamate receptor-mediated neurotoxicity. Our findings reveal a novel function of alsin in AMPA receptor trafficking and provide a novel pathogenic link between ALS2-deficiency and motor neuron degeneration, suggesting a protective role of alsin in maintaining the survival of motor neurons.

Key words: ALS2; knock-out mouse; motor neuron; GRIP1; AMPA receptor; excitotoxicity

\section{Introduction}

Amyotrophic lateral sclerosis (ALS) is the most common adultonset motor neuron disease (Cleveland and Rothstein, 2001; Bruijn et al., 2004). One form of juvenile onset autosomal recessive ALS (ALS2) has been linked to the loss of function of the ALS2 gene (Hadano et al., 2001; Yang et al., 2001). Alsin encoded by the full-length ALS2 gene contains three putative guaninenucleotide-exchange factor (GEF)-like domains. The aminoterminal regulator of chromatin condensation like domain

\footnotetext{
Received May 16, 2006; revised Aug. 31, 2006; accepted 0ct. 4, 2006.

This work was supported in part by the Intramural Research Program of the National Institutes of Health (NIH) National Institute on Aging (H.C., M.C.), a joint grant from the Amyotrophic Lateral Sclerosis (ALS) Association and the Robert Packard Center for ALS Research at the Johns Hopkins University (H.C., P.C.W.), and National Institute of Neurological Disorders and Stroke Grants NS40014 (P.C.W.), NS34100 and NS52098 (L.J.M.), and NS053570 (J.J.Z.). S.G.M. receives an NIH Predoctoral Training Fellowship, M.K.M is a visiting student receiving a fellowship from the University of Virginia-Technical University of Łódź, Poland graduate exchange program, and J.J.Z. is an Alfred P. Sloan Fellow. We thank Drs. Yamanaka and Cleveland (University of California at San Diego, La Jolla, CA) for the monoclonal ALS2 antibodies, Carol Coccia for assistance with the organotypic spinal cord slice culture, and the NIH Fellows Editorial Board for editing this manuscript.

Correspondence should be addressed to Dr. Huaibin Cai, Section of Transgenesis, Laboratory of Neurogenetics, National Institute on Aging, National Institutes of Health, Building 35, Room 1A116, 35 Convent Drive, Bethesda, MD 20892-3707. E-mail: caih@mail.nih.gov.

DOI:10.1523/JNEUROSCI.2084-06.2006

Copyright $\odot 2006$ Society for Neuroscience $\quad$ 0270-6474/06/2611798- $\bullet \$ 15.00 / 0$
}

(RLD) resembles the GEF for Ran GTPase. The middle Dbl homology (DH)- and pleckstrin homology (PH)-like domains are similar to the GEF of Rho GTPase. The carboxyl-terminal vacuolar protein sorting 9 (VPS9)-like domain is homologous to the GEF of Rab GTPase. Most mutations in the ALS2 gene lead to premature stop codons resulting in carboxyl-terminal truncated proteins that are unstable compared with the wild-type alsin (Yamanaka et al., 2003). Most recently, two homozygous missense mutations in the RLD domain of alsin have been identified, but how they affect the function of alsin is unclear (EymardPierre et al., 2006; Panzeri et al., 2006). Loss of function of alsin causes the degeneration of motor neurons (Hadano et al., 2001; Yang et al., 2001; Kress et al., 2005), however, the pathogenic mechanism of ALS2 remains unknown. ALS2 knock-out $\left(A L S 2^{-/-}\right)$mice display subtle motor deficits and neuropathological abnormalities, but fail to develop motor neuron degeneration as seen in the human disease (Cai et al., 2005; Devon et al., 2006; Hadano et al., 2006; Yamanaka et al., 2006), suggesting that alsin may serve as a protective factor for motor neurons against genetic or environmental insults.

Glutamate-mediated excitotoxicity, primarily mediated by AMPA-type glutamate receptors (AMPAR) in spinal motor neurons, contributes to the sporadic ALS (Kwak and Weiss, 2006). 
AMPARs are tetramers composed of various combinations of the GluR1-4 subunits in which GluR2 is particularly important because GluR2-containing AMPARs are calcium-impermeable and neurons lacking GluR2-containing AMPARs are more vulnerable to excitotoxicity (Kwak and Weiss, 2006). The presentation of GluR2 at the synaptic surface is dynamically regulated through its binding proteins, including glutamate receptor interacting protein 1 (GRIP1). GRIP1 transports GluR2 to dendrites and anchors GluR2 in both postsynaptic membrane and intracellular compartments (Setou et al., 2002; Song and Huganir, 2002).

The RLD domain of alsin displays little proposed Ran GEF activity but may serve as a protein-protein interaction domain (Otomo et al., 2003). To decipher the molecular network in which alsin is involved, we screened proteins interacting with its RLD domain. We found that the RLD domain of alsin interacted with the postsynaptic density 95 (PSD-95)/Dlg/ZO-1 (PDZ) domains of GRIP1 and loss of alsin altered the subcellular localization of GRIP1, which correlated with a reduction of GluR2 at the cell/synaptic surface of $A L S 2^{-/-}$neurons, resulting in an increased vulnerability of these neurons to excitotoxicity. Here, we reveal a novel function of alsin in AMPAR trafficking and provide a novel molecular pathway linking alsin-deficiency with motor neuron degeneration, which may serve as the therapeutic target for the treatment of ALS2 and related motor neuron diseases.

\section{Materials and Methods}

Animals. The generation of ALS2 knock-out mice was performed as described previously (Cai et al., 2005). Mice were housed in a $12 \mathrm{~h}$ light/ dark cycle and fed a regular diet ad libitum. The experimental protocols used are in accordance with the guidelines of the Institutional Animal Care and Use Committees of the Johns Hopkins University, the University of Virginia School of Medicine, and the National Institute on Aging.

Expression constructs. The full-length mouse ALS2 cDNA clone was obtained by a combination of $5^{\prime}$ rapid amplification of cDNA ends PCR and screening of a mouse brain cDNA library (Origene, Rockville, MD). The RLD, DH/PH, and VPS9 domains of alsin residues 1-666, 6561257 , and 1169-1657 were made by PCR amplification of ALS2 fulllength cDNA and verified by sequencing. ALS2 constructs were subcloned into modified pRK5 expression vectors, which were tagged with myc, hemagglutinin (HA), glutathione $S$-transferase (GST), or enhanced green fluorescent protein (EGFP) at the $\mathrm{N}$ terminus.

Antibodies. Alsin monoclonal antibodies (1:1000) were gifts from Dr. Don Cleveland (University of California at San Diego, La Jolla, CA) (Yamanaka et al., 2006). The GRIP1 (1:2000), GluR1 (1:1000), GluR2/3 (1:1000), and NR1 (1:1000) antibodies (Upstate Biotechnology, Charlottesville, VA); the GluR3 (1:1000), GluR2 (1:1000), and actin (1:5000) antibodies (Millipore, Temecula, CA); the protein interacting with C-kinase 1 (PICK1) (1:1000) and GFP (1:1000) antibodies (ABCAM, Cambridge, UK); the $\beta$ III-tubulin antibody (1:5000; Covance, Berkeley, CA); synaptophysin antibody (1:1000; Sigma, St. Louis, MO); myc and HA antibodies (1:5000; Roche, Indianapolis, IN); and, the GST antibody (1:2000; Amersham, Piscataway, NJ) were used as suggested by the manufacturers. The alsin polyclonal antibody (1:1000), ALS2-1081, was made by immunizing rabbit with a polypeptide corresponding to alsin residues 1081-1110 (Yamanaka et al., 2003).

Transfection of HEK293 cells, coimmunoprecipitation, membrane preparations, subcellular fractionations, and pull-down assays. Transfection of human embryonic kidney 293 (HEK293) cells, coimmunoprecipitation, subcellular fractionations, membrane preparations, and solubilizations were performed as before (Cai and Reed, 1999; Dong et al., 1999). For pull-down assays, the clarified crude synaptosomal fraction (P2) of brain homogenates was added to the GRIP1-bound HA-affinity matrix (Roche) and incubated for $2 \mathrm{~h}$ at $4^{\circ} \mathrm{C}$. After incubation, the mixture was washed once with Tris-buffered saline (TBS) $(1 \times$ TBS, $10 \mathrm{~mm}$ Tris 8.0, $150 \mathrm{~mm} \mathrm{NaCl}$ ) containing $1 \%$ Nonidet P-40, twice with TBS buffer containing $300 \mathrm{~mm} \mathrm{NaCl}$, and three times with TBS buffer alone. Finally, the proteins were eluted by SDS sample buffer and subjected to Western blot.
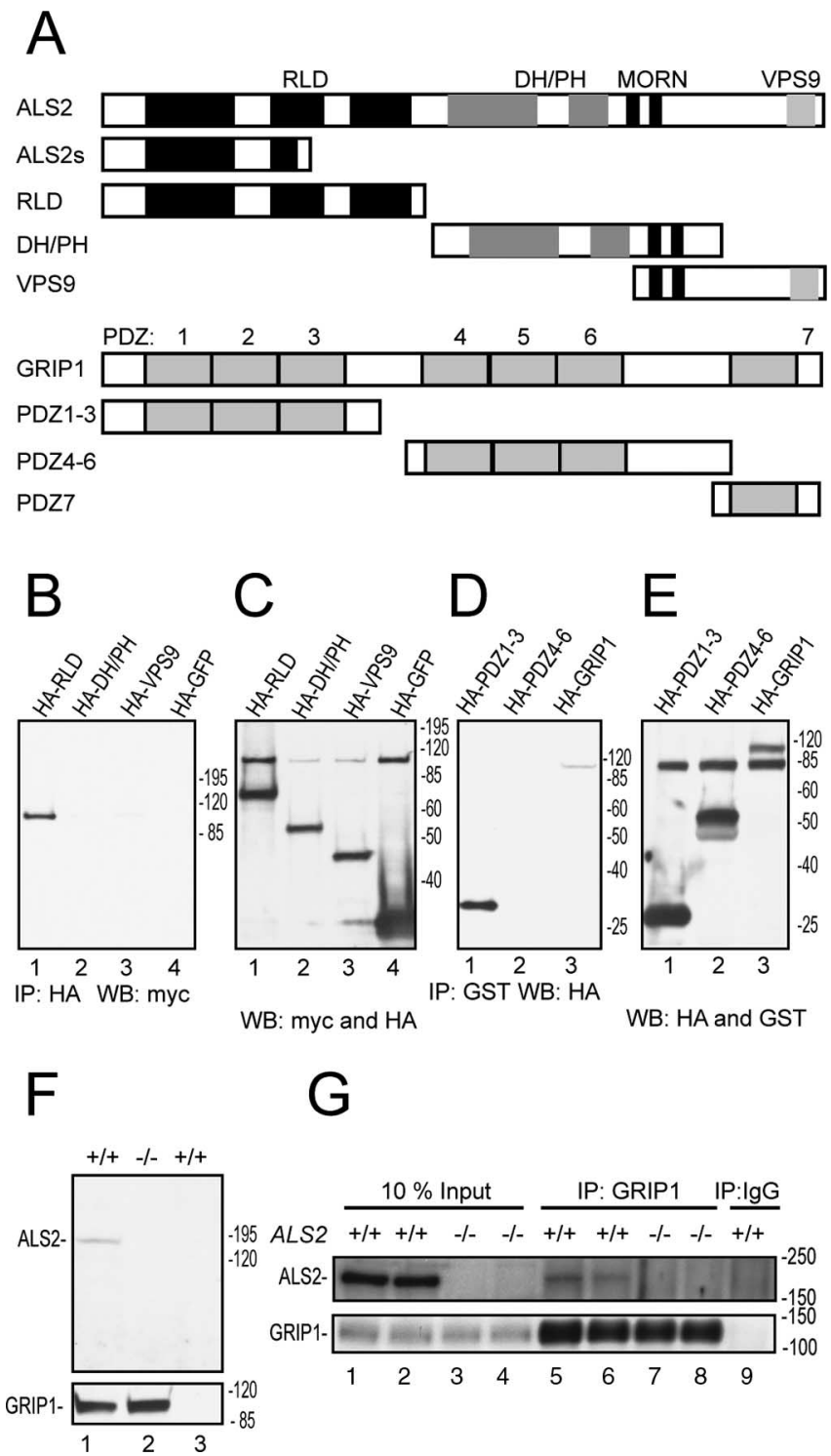

Figure 1. Alsin interacts with GRIP1. A, Schematic representation of ALS2 and GRIP1 expression constructs. Conserved domains within ALS2 include an amino-terminal RLD, a middle DH and PH-like domain, and a carboxyl-terminal VPS9-like domain in conjunction with an upstream membrane occupation and recognition nexus (MORN) motifs. GRIP1 contains seven PDZ domains. $B$, Myc-tagged GRIP1 was coexpressed with HA-tagged RLD, DH/PH, and VPS9 domains of alsin in HEK293 cells. The presence of GRIP1 in the immunoprecipates was detected with an anti-myc antibody. C, The expression of myc-GRIP1 in the total cell lysates was detected by an anti-myc antibody and the expression of HA-RLD (lane 1), HA-DH/PH (lane 2), HA-VPS9 (lane 3), and HA-GFP (lane 4) in the total cell lysates were detected by an anti-HA antibody. $\boldsymbol{D}$, The GST-tagged RLD domain of alsin was coexpressed with HA-tagged PDZ1-3, PDZ4 - 6, and full-length GRIP1 in HEK293 cells. The full-length GRIP1 and its PDZ1-3 but not PDZ4 - 6 were pulled down together with the RLD domain of alsin and detected by an anti-HA antibody. $\boldsymbol{E}$, The expression of GST-RLD of alsin in total cell lysates was detected by an anti-GST antibody and the expression of HA-PDZ1-3 (lane 1), HA-PDZ4 - 6 (lane 2), and HA-GRIP1 (lane 3) in total cell lysates was detected by an anti-HA antibody. $\boldsymbol{F}$, The $\mathrm{P} 2$ fraction of cerebellar homogenates prepared from ALS2 wild-type $(+/+)$ (lane 1) or knock-out (-/-) (lane 2) mice was incubated with purified HA-tagged GRIP1 and pulled down by anti-HA affinity matrix. In a separate control, the P2 fraction of cerebellar homogenate prepared from ALS2 wild-type mice $(+/+)$ (lane 3) was pulled down by anti-HA affinity matrix (preincubated with nontransfected HEK293 cell lysate) alone. The presence of alsin in the immunoprecipate was detected by Western blot using the polyclonal alsin antibody. G, GRIP1-containing protein complex was immunoprecipitated from wild-type (lanes 5, 6) and ALS2 ${ }^{-1-}$ (lanes 7, 8) whole-brain lysates by a GRIP1 specific rabbit polyclonal antibody. As a control, normal rabbit lgG was used in parallel with GRIP1 antibody (lane 9). The presence of alsin in brain lysates and immunoprecipitates was detected by Western blot using the alsin polyclonal antibody. 
Transfection, immunocytochemistry, and confocal imaging of neurons. The primary neuronal culture was prepared as described previously (Cai et al., 2005). Hippocampal neurons were transfected $10 \mathrm{~d}$ after culture using Effectene transfection reagent (Qiagen, Valencia, CA). Four days after transfection, neurons were fixed with $4 \%$ paraformaldehyde (PFA) and $4 \%$ sucrose for $15 \mathrm{~min}$, permeabilized with $0.1 \%$ Triton X-100 in $1 \times$ PBS for 10 min, blocked with $10 \%$ normal goat serum at room temperature for $1 \mathrm{~h}$, and incubated with primary antibody at $4^{\circ} \mathrm{C}$ overnight. Cells were then washed three times with $1 \times$ PBS and incubated with Alexa 488 or Alexa 568 conjugated secondary antibody (1:1000 dilution) at room temperature for $1 \mathrm{~h}$. Finally, cells were washed three times with $1 \times$ PBS and mounted with ProLong Gold antifade reagent (Invitrogen, Eugene, OR). Fluorescence images were captured using a laser scanning confocal microscope (LSM 510; Zeiss, Thornwood, NJ). Images were scanned using a $63 \times 1.4$ numerical aperture (NA) oil objective or a $100 \times 1.4$ NA oil objective lens. A zoom factor of 2 was used to obtain maximum resolution of $100 \times$ images. Some images were acquired in $z$-series stack scans at $1 \mu \mathrm{m}$ intervals from individual fields to determine the proteinprotein colocalization. Maximum intensity projections were used to represent confocal stacks. For the quantitative assessment of GRIP1, PICK1, or synaptophysin accumulation in the soma or synapse of spinal motor neurons, images were taken using identical settings. The data were analyzed using repeated measures or simple main effect two-tailed $t$ tests.

Electrophysiology. The preparation of brain slices including the sensorimotor cortex from 2- to 3-week-old ALS2 knock-out and wild-type mice ( $n=8$ /group) were as described in previous reports (Larkum and Zhu, 2002). Brain slices were kept at $37.0 \pm 0.5^{\circ} \mathrm{C}$ in oxygenated physiological solution for $\sim 1 \mathrm{~h}$ before recordings were made. During the recording, the slices were submerged in a chamber and stabilized with a fine nylon net attached to a platinum ring. The chamber was perfused with oxygenated physiological solution, the halftime for the bath solution exchange being $\sim 6 \mathrm{~s}$. Whole-cell recordings were made on layer $2 / 3$ pyramidal neurons by using infrared illumination combined with differential interference contrast optics. Patch recording pipettes (3-6 M $\Omega$ ) contained the following (in mM): 115 cesium methanesulfonate, $20 \mathrm{CsCl}, 10 \mathrm{HEPES}$, $2.5 \mathrm{MgCl}_{2}, 4 \mathrm{Na}_{2} \mathrm{ATP}, 0.4 \mathrm{Na}_{3} \mathrm{GTP}, 10$ sodium phosphocreatine, $0.6 \mathrm{EGTA}$, and 0.1 spermine, $\mathrm{pH} 7.25$, for current (voltage-clamp) recordings. Wholecell recordings were made with an Axopatch-200B amplifier (Molecular Devices, Foster City, CA). Synaptic responses were evoked by bipolar electrodes with single voltage pulses $(200 \mu$ s, up to $20 \mathrm{~V})$ placed in the layers 5 and $6, \sim 100-300 \mu \mathrm{m}$ lateral from the cells that were recorded. Synaptic AMPA responses at -60 and $+40 \mathrm{mV}$ were averaged over 50-90 trials and their ratio was used as an index of rectification following previous studies (Zhu et al., 2000; Qin et al., 2005; McCormack et al., 2006). To minimize the effect from AMPA responses, the peak NMDA responses at $+40 \mathrm{mV}$ were measured after digital subtraction of estimated AMPA responses at +40 $\mathrm{mV}$. All results are reported as mean $\pm \mathrm{SEM}$, and statistical differences of the means were determined using Mann-Whitney rank sum nonparametric test.

Plasma membrane protein biotinylation assay. Before biotinylation, cultured cortical neurons were treated with either $100 \mu \mathrm{M}$ AMPA or saline for $5 \mathrm{~min}$ at $37^{\circ} \mathrm{C}$ as described previously (Lee et al., 2004), replenished with fresh medium, and incubated for $10 \mathrm{~min}$ at $37^{\circ} \mathrm{C}$. The surface biotinylation assay was performed as reported previously (Mammen et al., 1997). Total
S1 P1 S2 P2 LM 0.85 Syn PSD Mit

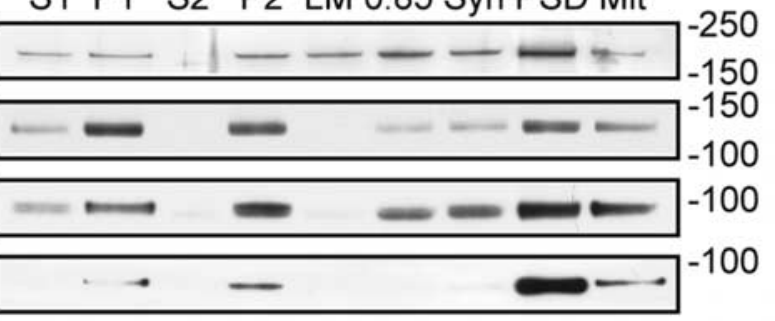
$-150$ $-150$ $-100$ (10)
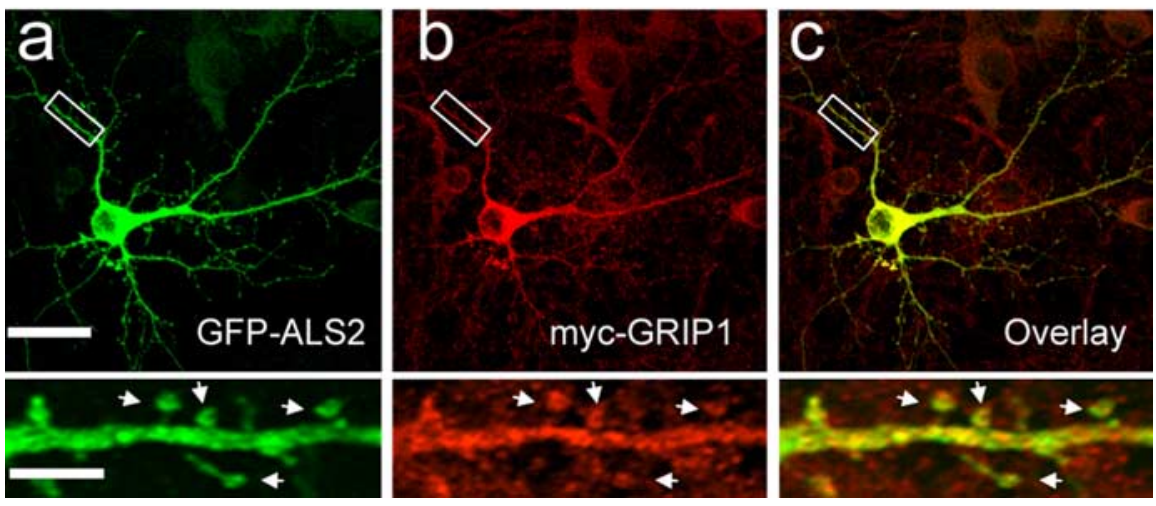

Figure 2. Alsin colocalizes with GRIP1. A, Subcellular fractionation of alsin, GRIP1, GluR2, and PSD95. Whole-brain lysate was fractionated into several subcellular fractions, including the soluble (S1), nuclear (P1), cytosol (S2), crude synaptosomal fraction (P2), light membrane (LM), layer between 0.8 and $1.0 \mathrm{~m}$ sucrose (0.85), synaptic plasma membrane fraction (Syn), PSD, and cotransfected into cultured hippocampal neurons and immunostained with antibodies against GFP and myc, respectively. ALS2 (green) and GRIP1 (red) colocalized in the dendritic spines (arrows, bottom) as revealed by confocal microscopy. The bottom panels are the enlargements of boxed areas in upper panels. Scale bars: $\boldsymbol{B}$, top, $20 \mu \mathrm{m}$; bottom, $5 \mu \mathrm{m}$.

protein and isolated biotinylated protein were analyzed by quantitative immunoblotting with anti-GluR2, GluR3, GluR2/3, GluR1, NR1, ALS2, and $\beta$ III-tubulin antibodies. All of the immunoblots were visualized by enhanced chemiluminescence development (Pierce, Rockford, IL) and quantified on a Scion (Frederick, MD) Image System. The data were analyzed using repeated-measures or simple main effect two-tailed $t$ tests.

AMPA treatment and neuron survival analysis. Cortical neurons after 2 weeks in culture were treated with 5, 25, and $50 \mu \mathrm{M}$ AMPA (Sigma) for $24 \mathrm{~h}$. The lactate dehydrogenase ( $\mathrm{LDH})$ assay was used to determine the survival rate of neurons treated with AMPA as described previously (Cai et al., 2005). The data were analyzed using repeated-measures or simple main effect two-tailed $t$ tests.

Organotypic spinal cord slice culture and treatment. The organotypic spinal cord cultures were prepared from the postnatal day 7 mouse pups similar to those described previously (Rothstein et al., 1993). Spinal cords were sectioned transversely at $300 \mu \mathrm{m}$ intervals using a McIlwain tissue chopper. Sections were placed on $30 \mathrm{~mm}$ semipermeable Millipore Millicell membranes (five slices per membrane) in a six-well plate containing $1 \mathrm{ml}$ of culture medium [ $50 \%$ MEM, 25\% heat-inactivated horse serum, $25 \%$ HBSS supplemented with glucose $(12.8 \mathrm{~g} / 500 \mathrm{ml})$ and $2 \mathrm{~mm}$ L-glutamine]. Cultures were maintained in a humidified environment at $37^{\circ} \mathrm{C}$, in a $5 \% \mathrm{CO}_{2}$ incubator. Medium was changed every $3 \mathrm{~d}$ along with any treatments. Cultures were allowed to recover for $7 \mathrm{~d}$ before being subjected to 10 or $25 \mu \mathrm{M}$ AMPA treatment for $14 \mathrm{~d}$. After treatment, spinal cord slices were fixed with $4 \%$ PFA and stained with a monoclonal antibody, SMI32 (Sternberger Monoclonals, Lutherville, MD). The 

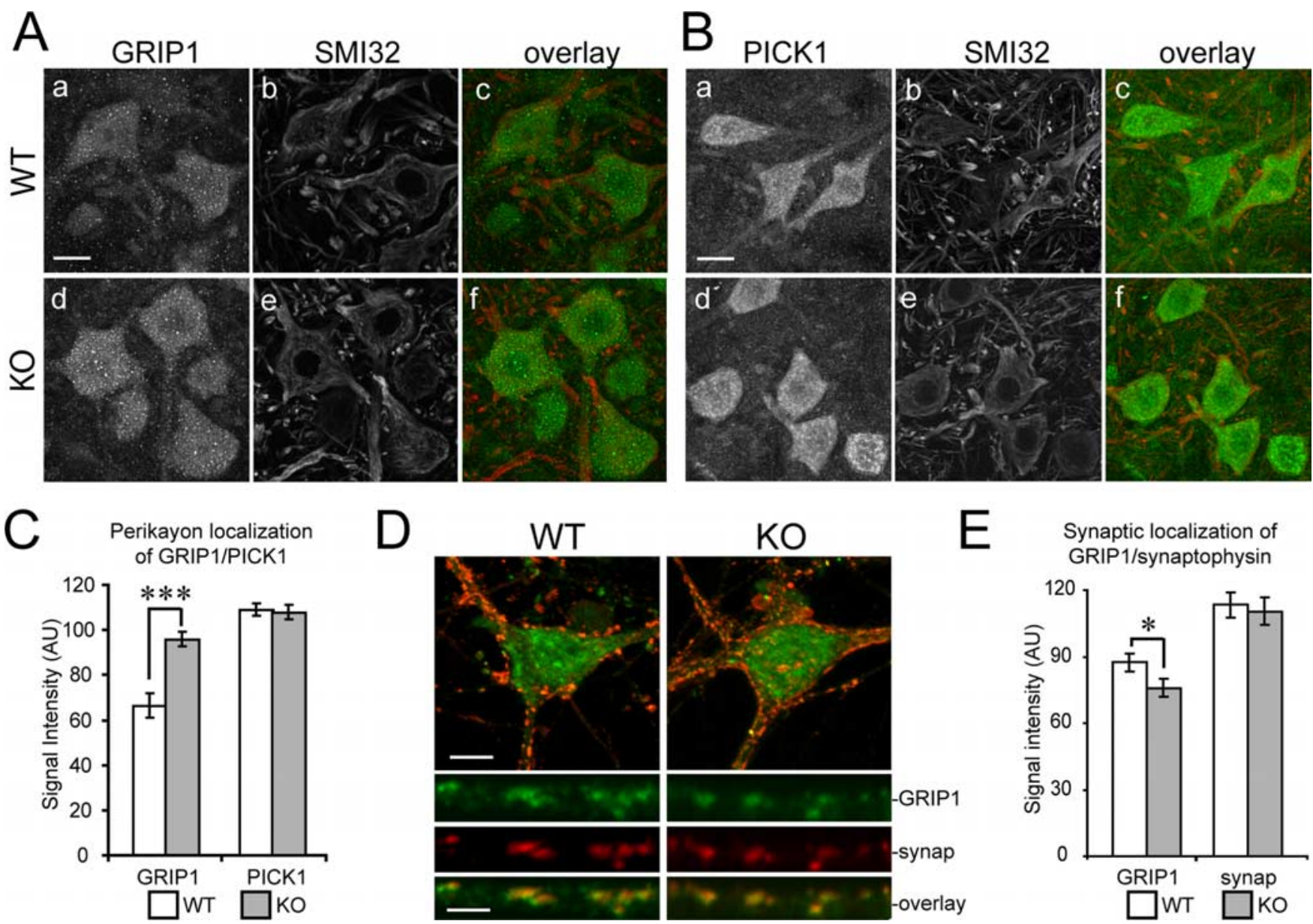

Figure 3. Increased accumulation of GRIP1 in perikaryon and decreased accumulation of GRIP1 in synapses in ALS2 ${ }^{-/-}$spinal cord motor neurons. $A$, Representative images of GRIP1 immunostaining revealed a discrete and punctate staining pattern of GRIP1 in the soma of $A L S 2^{-/-}(K 0, \boldsymbol{A d})$ and wild-type spinal motor neurons (WT, $\left.A \boldsymbol{a}\right)$. Spinal motor neurons were revealed by immunostaining with SMI32 antibody $(\boldsymbol{A} \boldsymbol{b}, \boldsymbol{A e}) \cdot \boldsymbol{B}$, Representative images of PICK1 immunostaining showed a similar staining pattern as GRIP1 in the soma of $A L S 2^{-/-}(\boldsymbol{B d})$ and wild-type spinal motor neurons $(\boldsymbol{B a})$. Spinal motor neurons were revealed by immunostaining with SMI32 antibody $(\boldsymbol{B b}, \boldsymbol{B} \boldsymbol{e})$. $\boldsymbol{C}$, The bar graph shows that the accumulation of GRIP1, but not PICK1, is significantly increased in the soma of $A L S 2^{-/-}$spinal motor neurons $(n=10)$ as compared with the wild-type controls $\left(n=9 ;{ }^{* * *} p<0.001\right)$. The fluorescence signal of GRIP1 or PICK1 is normalized with SMI32 and represented as an arbitrary unit. D, Representative images of wild-type (left) and $A L S 2^{-1-}$ (right) spinal motor neurons (top) and their dendrites (bottom) immunostained with GRIP1 (green) and synaptophysin (synap; red). $\boldsymbol{E}$, The bar graph shows mean values (arbitrary unit) of GRIP1 and synaptophysin fluorescence intensities after background subtraction at synapses (WT, $n=19 \mathrm{vs}$ $\mathrm{K} 0, n=20$ ). Error bars represent SEM. ${ }^{*} p<0.05$. Scale bars: $\boldsymbol{A}, \boldsymbol{B}, 20 \mu \mathrm{m} ; \boldsymbol{D}$, low magnification images, $20 \mu \mathrm{m}$; high magnification images, $5 \mu \mathrm{m}$.

SMI32-positive large motor neurons $(>25 \mu \mathrm{m})$ in the ventral horn were counted from each slice. The data were analyzed using repeatedmeasures or simple main effect two-tailed $t$ tests.

Injection of spinal cord in vivo and immunohistochemistry. Adult (6-8 weeks old) wild-type and $A L S 2^{-/-}$mice $(n=7 /$ group) received spinal cord injections of kainic acid (KA; Sigma). KA was dissolved in $100 \mathrm{~mm}$ PBS, pH 7.4, and stored in the dark at $-20^{\circ} \mathrm{C}$ until used. Mice were deeply anesthetized (isoflurane/nitrous oxide/oxygen), placed in a stereotaxic apparatus (Stoelting, Wood Dale, IL), and prepared for surgery. After a laminectomy at L2, a stereotaxic injection of KA (2 nM in PBS) was made unilaterally directly into the ventral horn parenchyma of lumbar spinal cord using a mounted $10 \mu \mathrm{l}$ Hamilton syringe and a stainless-steel needle with a $10-12^{\circ}$ bevel angle. This dose of KA was chosen because we anticipated that it was near subthreshold for toxicity in vivo (PorteraCailliau et al., 1997). To prevent leakage of toxin from the injection site, the needle was left in place for $10 \mathrm{~min}$ before it was withdrawn slowly over $3 \mathrm{~min}$. Mice were anesthetized with an overdose of sodium pentobarbital at $24 \mathrm{~h}$ after KA injection and perfused intracardially with ice-cold PBS followed by ice-cold 4\% PFA in PBS. After perfusion-fixation, spinal cords remained in situ for $2 \mathrm{~h}$ before they were removed from the vertebral column. After the spinal cords were removed, the lumbar enlargements were cryoprotected in $20 \%$ glycerol-PBS and frozen under pulverized dry ice. Horizontal serial symmetrical sections $(40 \mu \mathrm{m})$ were cut using a sliding microtome and stored individually in 96-well plates. Sections were selected with a random start and then systematically sampled (every 10 sections) to generate a subsample of sections from each mouse lumbar spinal cord that were mounted on glass slides and stained with cresyl violet for neuronal counting. Counts of remaining motor neurons in the ipsilateral (lesioned) and contralateral (nonlesioned) ventral horns were made at $1000 \times$ magnification using the stereological optical dissector method as described previously (Martin and Liu, 2002). The criteria for a motor neuron included a round, open, pale nucleus (not condensed and darkly stained), globular Nissl staining of the cytoplasm, and a diameter of $\sim 30-45 \mu \mathrm{m}$. With these criteria, astrocytes, oligodendrocytes, and microglia were excluded from the counts. Neuronal counts were used to determine group means and variances and comparisons among groups were analyzed using a one-way ANOVA and a Newman-Keuls post hoc test.

\section{Results}

Interaction of alsin with GRIP1

To understand the physiological role of alsin and the pathogenic mechanism in ALS2-related motor neuron disease, we examined proteins interacting with the amino-terminal RLD domain of alsin. We found that the RLD domain of alsin strongly interacted 

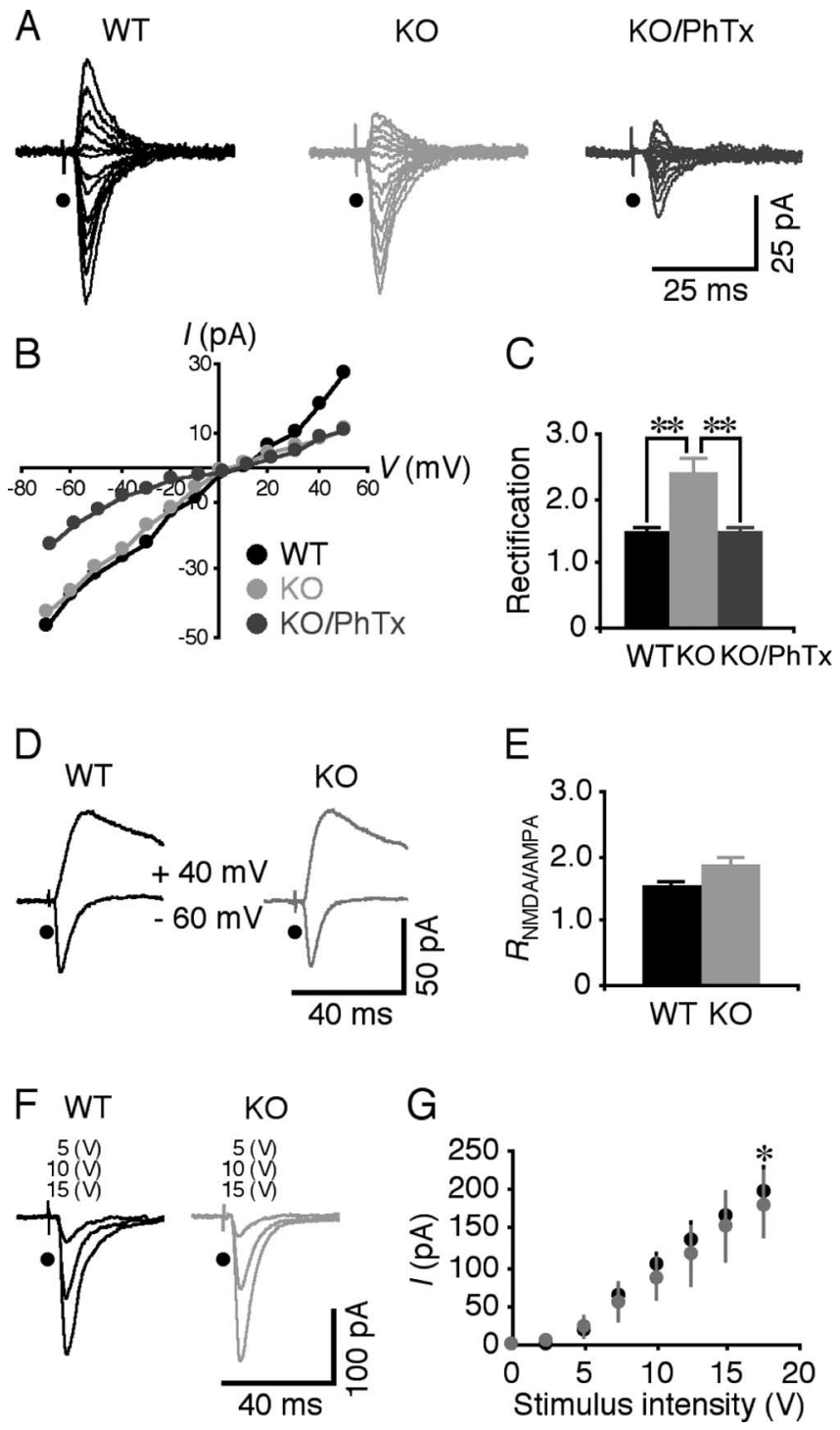

Figure 4. Increased ratio of synaptic GluR2-lacking AMPARs versus GluR2-containing AMPARs in $A L S 2^{-1-}$ cortical neurons. $A$, The evoked AMPAR-mediated responses from a wildtype and $A L S 2^{-/-}$neuron bathed in normal physiological solution containing additional 10 $\mu \mathrm{m}$ PhTx at different holding potentials (from $-60 \mathrm{mV}$ to $+40 \mathrm{mV}$ in $10 \mathrm{mV}$ steps). $\boldsymbol{B}$, The I-V plots of evoked responses from the wild-type and $A L S 2^{-1-}$ neurons shown in $A$. C, Bar graph shows that rectification of evoked AMPA responses (defined as the ratio of AMPA responses measured at $-60 \mathrm{mV}$ and $+40 \mathrm{mV}$ ) in WT and $\mathrm{KO}$ neurons. Note that rectification in $\mathrm{ALS} 2^{-1-}$ neurons bathed in normal physiological solution was significantly larger than those in WT neurons bathed in normal physiological solution and in $\mathrm{ALS}^{-1-}$ neurons bathed in normal physiological solution containing additional $10 \mu \mathrm{M} \mathrm{PhTx}$ (KO/PhTx; WT, $1.47 \pm 0.08, n=28$; $\left.\mathrm{KO}, 2.36 \pm 0.25, n=20 ; \mathrm{KO} / \mathrm{PhTx}, 1.46 \pm 0.09 n=27 ;^{* *} p<0.01\right)$. D, Evoked AMPAR- $(-60$ $\mathrm{mV})$ and NMDAR- $(+40 \mathrm{mV})$ mediated responses from wild-type and $A L S 2^{-/-}$neurons. $\boldsymbol{E}$, Bar graph shows that the ratio of NMDA and AMPA responses in $A L S 2^{-/-}$neurons was the same as that in wild-type neurons (WT, $1.52 \pm 0.07, n=31$ vs K0, $1.82 \pm 0.18, n=22 ; p=0.47$ ). $\boldsymbol{F}$, Evoked AMPAR-mediated responses from wild-type and $A L S 2^{-1-}$ neurons at different stimulation intensities. $\mathbf{G}$, Plot of the amplitudes of evoked AMPA responses in wild-type and $A L S 2^{-/-}$neurons against different stimulus intensities. ${ }^{*} p<0.05$ (Mann-Whitney rank sum nonparametric test).

with the amino-terminal three PDZ domain of GRIP1 in the protein pull-down assay (Fig. $1 \mathrm{~B}$ ), whereas the DH/PH and VPS9 domains did not show significant binding to GRIP1 (Fig. 1B). The short spliced form of alsin, containing a partial RLD domain, also bound to GRIP1 to a lesser extent (data not shown). Among the seven PDZ domains of GRIP1, the RLD domain of alsin selectively bound to the three most amino-terminal domains (Fig. $1 D)$. We found additional support for a direct interaction between alsin and GRIP1 by pulling down alsin from the crude synaptic membrane fraction of cerebellar lysate by affinitypurified HA-tagged GRIP1 (Fig. $1 F$ ). Moreover, endogenous alsin and GRIP1 were coimmunoprecipitated from brain extracts with a GRIP1-specific antibody (Fig. 1G), indicating that ALS2 and GRIP1 coexist in the same molecular complex in vivo. As a control, normal IgG (Fig. 1G) or PICK1- and PSD95-specific antibodies failed to pull down alsin from the same brain extracts (data not shown).

\section{Colocalization of alsin with GRIP1 in cultured hippocampal neurons}

The interaction between alsin and GRIP1 indicates a postsynaptic localization of alsin in neurons. To examine the synaptic localization of alsin, we purified the PSD fraction from brain homogenates in subcellular cell fractionation experiment. We found that alsin was abundant in the PSD fraction characterized by the enrichment of PSD95, a specific marker for the PSD (Fig. 2A). The presence of alsin in the synaptic membrane and PSD fractions is consistent with a previous report (Topp et al., 2004).

We then decided to examine the synaptic localization of alsin by immunocytochemistry. There are only a few reports on the localization of endogenous alsin in neurons (Topp et al., 2004; Jacquier et al., 2006). However, none of these experiments used $A L S 2^{-1-}$ neurons as the negative control. Nevertheless, these studies suggest that a significant fraction of alsin is localized in punctate membrane structures distributed in soma, dendrites, and axons. In one study, the alsin immunoreactivity appears in dendritic spines (Topp et al., 2004). In our study, we have used one affinity-purified alsin polyclonal antibodies (Yamanaka et al., 2003) and three alsin monoclonal antibodies (Yamanaka et al., 2006) to detect the expression of alsin in cultured spinal motor neurons, cortical neurons, hippocampal neurons, and cerebellum granule cells. However, the same staining pattern and the signal intensity of alsin were revealed in both wild-type and $A L S 2^{-/-}$neurons (supplemental Fig. 1, available at www.jneurosci.org as supplemental material), indicating that these signals are false positive. To overcome this difficulty, we transfected amino-terminal tagged GFP-ALS2 and amino-terminal tagged myc-GRIP1 expression constructs into cultured hippocampal neurons. Double immunofluorescence labeling revealed high levels of colocalization of alsin and GRIP1 along dendritic spines (Fig. 2 B, bottom, arrows).

\section{Increased perikaryon accumulation and decreased synaptic} localization of GRIP1 in ALS2 $2^{-/-}$spinal motor neurons

To examine whether loss of ALS2 affects the accumulation of GRIP1 in neurons, we compared the expression of GRIP1 in spinal cord extracts of $A L S 2^{-/-}$and wild-type mice by Western blot. No significant alteration of GRIP1, GluR1, GluR2, GluR2/3, NR1 (NMDA receptor subunit 1), or PICK1 expression was detected in $A L S 2^{-/-}$spinal cord protein extracts (data not shown). Previous reports suggested a role for alsin in vesicular trafficking and microtubule organization (Otomo et al., 2003; Millecamps et al., 2005; Tudor et al., 2005). We then asked whether the loss of alsin affects the subcellular distribution of glutamate receptors or their interacting proteins in spinal motor neurons. We examined the expression pattern of these proteins in wild-type and $A L S 2^{-1-}$ lumbar spinal cord sections by immunofluorescence staining. Whereas the expression levels of PICK1 did not differ 
A

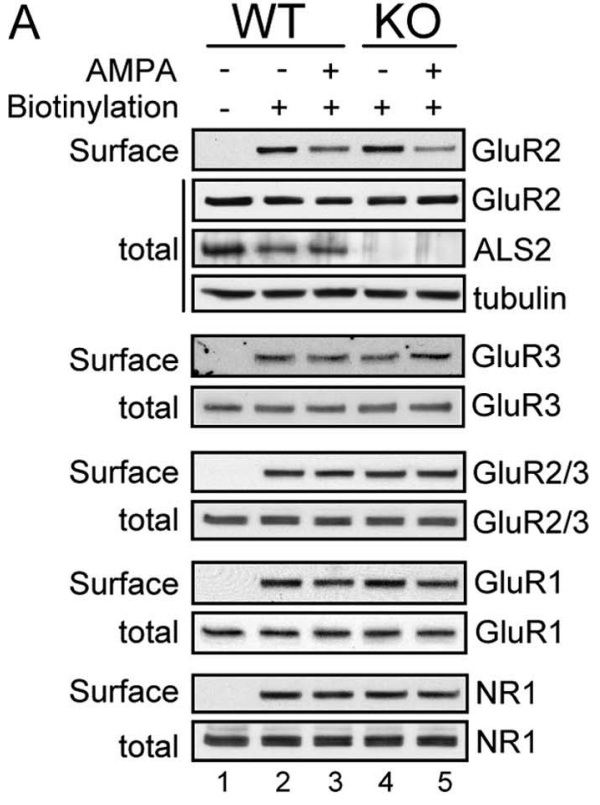

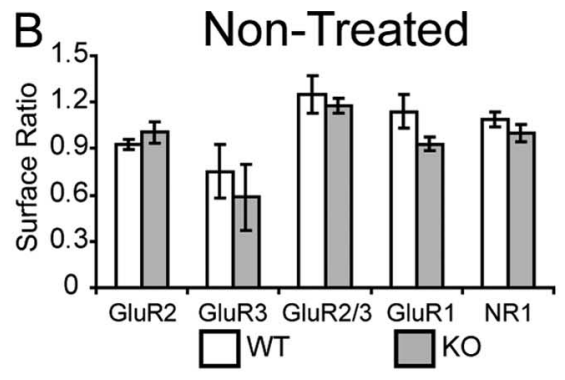

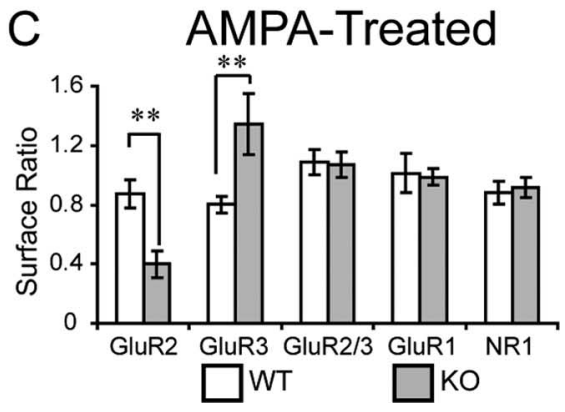

Figure 5. Decreased presentation of GluR2 at the plasma membrane of $A L S 2^{-/-}$cortical neurons after AMPA treatment. $\boldsymbol{A}$, Presentation of glutamate receptors at the cell surface of $K O$ neurons after AMPA treatment. Cortical neurons at $21 \mathrm{~d}$ in vitro were treated with either $100 \mu \mathrm{m}$ AMPA (lanes 3, 5) or saline (lanes 2,4) for 5 min before biotinylation. Equal dilution of unpurified (total) and NeutrAvidin-affinity purified proteins (surface) were analyzed by quantitative immunoblotting with anti-GluR1, GluR2, GluR3, GluR2/3, NR1, ALS2, and $\beta$ III-tubulin antibodies, respectively. $\boldsymbol{B}$, Bar graph shows that the surface fractions of GluR1, GluR2, GluR3, GluR2/3, and NR1 in WT and K0 neurons after the treatment of saline. C, Bar graph shows that the cell surface presentations of GluR1, GluR2, GluR3, GluR2/3, and NR1 in WT and KO neurons after the treatment of AMPA. ${ }^{* *} p<0.01$. Error bars represent SEM.

between wild-type and $A L S 2^{-1-}$ spinal motor neurons (Fig. $3 B, C)$, the accumulation of GRIP1 was significantly elevated in the perikaryon of $A L S 2^{-1-}$ spinal motor neurons (Fig. $3 A, C$ ). A discrete and punctate staining of GRIP1 appeared in the soma of $A L S 2^{-1-}$ spinal motor neurons resulting in a fluorescence intensity that was significantly higher compared with wild-type controls (Fig. 3A, $C)(n=9-10 ; p<0.001)$. As a control, we measured the fluorescence intensity of neurofilament $\mathrm{H}$ (visualized with the SMI32 antibody), and found comparable levels between $A L S 2^{-1-}$ and wild-type spinal motor neurons (Fig. 3A). The average size of motor neurons in these two groups had no significant difference (data not shown).

We then quantified the amount of GRIP1 in synapses. Because it is difficult to trace the synapses of individual motor neuron in slices, we assessed the synaptic expression of GRIP1 in isolated spinal

motor neurons after 4 weeks in culture. We measured the signal intensities of the postsynaptic GRIP1 and the presynaptic marker synaptophysin of each synapse after double-immunofluorescence

staining. Only well isolated synapses positive both for GRIP1 and synaptophysin staining were chosen for quantification. We observed a significant decrease in postsynaptic localization of GRIP1 in $A L S 2^{-/-}$motor neurons compared with wild-type controls (Fig. 3D,E) $(n=19-20$ synapses per neuron; three neurons per each genotype; $p<0.01$ ), whereas, no significance difference in signal intensities of synaptophysin was observed (Fig. $3 D, E)(p=0.11)$. However, we did not observe a similar alteration of GRIP1 accumulation in the perikaryon of cultured $A L S 2^{-/-}$spinal motor neurons (Fig. $3 D)$. We notice that the expression of GRIP1 in the soma was significantly lower in cultured spinal motor neurons com- pared with spinal cord slices (Figs. $3 A, D)$, which makes it difficult to quantify the GRIP1 fluorescence signals. Nevertheless, the alteration in subcellular distribution of GRIP1 in ALS2 $2^{-/-}$motor neurons implies a role for alsin in modulating intracellular protein trafficking and localization.

Increased ratio of synaptic GluR2-lacking AMPARs versus GluR2-containing AMPARs in $A L S 2^{-/-}$cortical neurons

Because we observed alterations of subcellular localization of GRIP1 in $A L S 2^{-/-}$ neurons (Fig. 3) and GRIP1 regulates GluR2 targeting to synapses (Song and Huganir, 2002; Cull-Candy et al., 2006), we speculated that GluR2-containing AMPARs could be downregulated in $A L S 2^{-1-}$ neurons. To test this hypothesis, we compared the evoked synaptic responses in cortical layer $2 / 3$ pyramidal neurons in wild-type and $A L S 2^{-/-}$mice. We found a significantly enhanced rectification of AMPAR-mediated responses in $A L S 2^{-1-}$ neurons compared with wild-type neurons (Fig. $4 A-C$ ), suggesting an increase of GluR2-lacking AMPARs and/or a decrease of GluR2-containing AMPARs at synapses. Bath application of $10 \mu \mathrm{M}$ philanthotoxin-433 (PhTx), which selectively blocks GluR2-lacking AMPARs (Toth and McBain, 1998), reduced the rectification of AMPA responses in $A L S 2^{-/-}$neurons to a value comparable with wild-type neurons (Fig. $4 A-C$ ). In contrast, the NMDA/AMPA ratio and input-output response curve were similar in both $A L S 2^{-/-}$and wild-type neurons (Fig. $4 D-G)$. Together, these results indicate that some GluR2containing AMPARs are replaced by GluR2-lacking AMPARs at synapses in $A L S 2^{-/-}$neurons and suggest that ALS2 may mediate the synaptic targeting of GluR2-containing AMPARs through an interaction with GRIP1.

\section{Decreased presentation of GluR2 at the plasma membrane of ALS $2^{-/-}$cortical neurons after AMPA treatment}

To further quantify the level of GluR2-containing AMPARs at the plasma membrane, we biotinylated and purified plasma membrane proteins from cultured cortical neurons. We found that the surface expression of GluR1, GluR2, GluR3, GluR2/3, and NR1 was comparable between wild-type and $A L S 2^{-1-}$ neurons (Fig. $5 A, B)(n=12 ; p>0.1)$. These results indicate that recycling of GluR2-containing AMPARs to the extrasynaptic plasma membrane, where the majority of AMPARs are located (Shi et al., 1999; Zamanillo et al., 1999), is not affected in $A L S 2^{-/-}$neurons in the native state. We then treated wild-type and $A L S 2^{-/-}$neurons with AMPA to increase the internalization of extrasynaptic AMPARs (Lin et al., 2000). After AMPA treatment, a significant reduction in cell surface expression of GluR2 was observed in ALS2 $2^{-/-}$neurons compared with wild-type controls (Fig. 5 A, C) $(n=6 ; p<0.01)$. In contrast, cell surface expression of GluR3 was significantly increased in $A L S 2^{-/-}$neurons after AMPA treatment (Fig. $5 A, C)(n=6 ; p<0.01)$. Meanwhile, no significant changes of GluR1, GluR2/3, or NR1 were detected between wild-type and $A L S 2^{-/-}$neurons after AMPA treatment (Fig. $5 C$ ). 
These results suggest that a diminished recycling of GluR2-containing AMPARs to synaptic and/or extrasynaptic membrane sites in $A L S 2^{-1-}$ neurons may increase the relative contribution of GluR2-lacking AMPARs at the cell/synaptic surface.

\section{Increased susceptibility to glutamate receptor-mediated excitotoxicity in $A L S 2^{-/-}$spinal motor neurons}

Previous studies have suggested that upregulation of calcium-permeable GluR2lacking AMPARs from the cell/synaptic surface renders neurons more vulnerable to glutamate-mediated excitotoxicity (Kwak and Weiss, 2006). To investigate whether the downregulation of GluR2containing AMPARs and upregulation of GluR2-lacking AMPARs in ALS2 $2^{-/-}$neurons increases the susceptibility of neurons to excitotoxicity, we treated cultured cortical neurons with different doses of AMPA. We found that the survival rate of ALS2 ${ }^{-/-}$neurons after treatment with AMPA was significantly lower compared with wild-type controls (Fig. 6A) $(p<$ 0.001 and 0.05 in $25 \mu \mathrm{M}$ AMPA and $50 \mu \mathrm{M}$ AMPA treatment, respectively). To examine whether $A L S 2^{-/-}$spinal motor neurons are more susceptible to excitotoxicity, we treated organotypic lumbar spinal cord slices with 10 or $25 \mu \mathrm{M}$ of AMPA for 2 weeks. Motor neurons were revealed by immunostaining with the SMI32 antibody as described previously (Maragakis et al., 2003). There were no differences in the number of motor neurons in vehicle-treated wild-type (WT) and $A L S 2^{-1-}(\mathrm{KO}) \mathrm{cul}-$ tures (Fig. $6 B, C)(\mathrm{WT}, 23.5 \pm 1.1$ per slice, $n=37$ vs KO, $22.7 \pm$ 1.1 per slice, $n=44 ; p=0.6)$. However, there was significantly more motor neuron loss in $A L S 2^{-1-}$ cultures compared with wild-type controls after treatment with $10 \mu \mathrm{M}$ (Fig. 6C) (WT, $20.0 \pm 0.9$ per slice, $n=29$ vs KO, $15.1 \pm 0.9$ per slice, $n=35$; $p<$ 0.001 ) or $25 \mu \mathrm{M}$ AMPA (Fig. $6 B, C$ ) (WT, $17.0 \pm 0.8$ per slice, $n=$ 30 vs KO, $13.1 \pm 0.9$ per slice, $n=27 ; p<0.01)$. To further examine whether $A L S 2^{-/-}$spinal motor neurons are more vulnerable to excitotoxic challenge in vivo, we made a unilateral stereotaxic injection of $\mathrm{KA}$, another glutamate analog, into the ventral horn parenchyma of the lumbar spinal cord. A single (2 $\mu \mathrm{l}$ ) injection of $1 \mathrm{mM} \mathrm{KA}$ resulted in a $13 \%$ loss of L2 motor neurons of wild-type mice (Fig. $6 D, E$ ). In contrast, the same KA challenge induced approximately a $52 \%$ loss of L 2 motor neurons of $A L S 2^{-/-}$mice (Fig. $6 D, E$ ) (WT, $87 \pm 11 \%$ vs KO, $48 \pm 15 \%$ survival rate; $n=7$ each; $p<0.001)$. Together, these observations demonstrate that $A L S 2^{-/-}$spinal motor neurons are more susceptible to glutamate receptor-mediated excitotoxicity.

\section{Discussion}

Here, we provide a direct link between loss of function of alsin and increased vulnerability of motor neurons to the excitotoxicity. We find that alsin interacts with GRIP1, a key regulator of synaptic targeting of GluR2. Furthermore, a lack of alsin leads to downregulation of GRIP1 in synapses, resulting in an increase in synaptic/cell surface localization of calcium-permeable AMPARs and a subseD, $260 \mu \mathrm{m} .{ }^{*} p<0.001$.
B
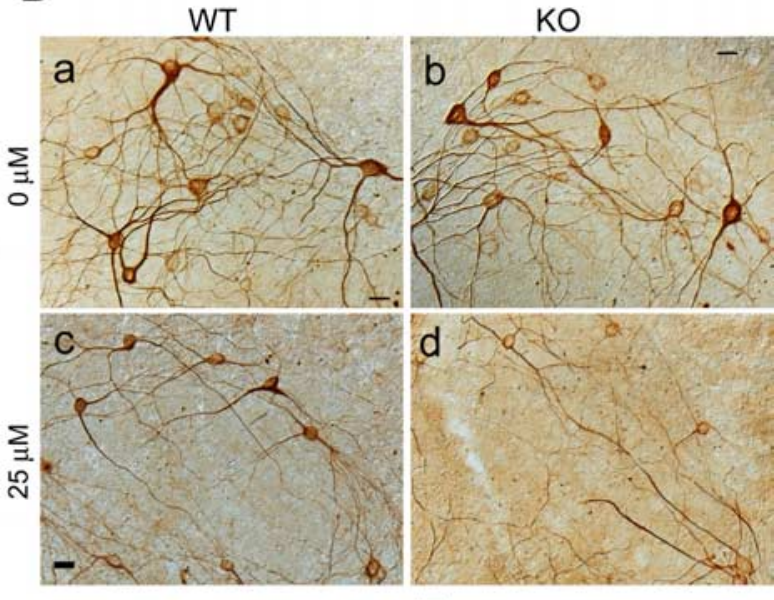

$E$

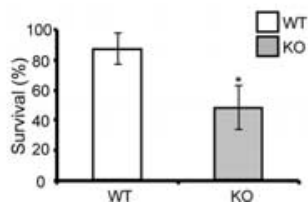

Figure 6. $\mathrm{ALS2} 2^{-1-}$ spinal motor neurons are more vulnerable to AMPA or KA-mediated excitotoxicity. $\boldsymbol{A}$, Primary cortical neurons were treated with AMPA, and the viability of these neurons was measured by the LDH assay. Each data point represented 列 shows the average numbers of SMI 32-positive spinal motor neurons in each cultured spinal cord slice. Error bars represent SEM. analysis of the KA-induced motor neuron loss in the two different mouse genotypes. Error bars represent SD. Scale bars: $\boldsymbol{B}, 20 \mu \mathrm{m}$;

quent increased susceptibility of $A L S 2^{-/-}$spinal motor neurons to AMPA or kainic acid-induced neurotoxicity.

Although the function of the N-terminal RLD of alsin is still unclear, we show here that it selectively interacts with the first three PDZ domains of GRIP1. Coexpression of alsin and GRIP1 in cultured neurons revealed extensive colocalization of these two proteins, particularly in some vesicle-like structures in the dendritic shaft and spines. Although it remains to be determined whether endogenous ALS2 is located in the postsynaptic site by immunocytochemistry, cell fractionation experiments clearly show an enrichment of alsin in the PSD fraction. To further support a physiological interaction between ALS2 and GRIP1, we find that the subcellular distribution of GRIP1 is altered in $A L S 2^{-/-}$spinal motor neurons. The transportation of GRIP1 is mediated by kinesin family motor proteins and in kinesin heavy chain (KIF5b) knock-out cells, more GRIP1 is located in the center than the periphery of the cell (Setou et al., 2002). A missense mutation in KIF5A causes a form of autosomal dominant "pure" hereditary spastic paraplegia (SPG10) (Reid et al., 2002), which exhibits similar motor behavioral phenotypes as ALS2. Because a similar increased accumulation of GRIP1 is observed in perikaryon of $A L S 2^{-1-}$ spinal motor neurons, it will be interesting to examine whether the kinesin-mediated transport of GRIP1 is impaired in $A L S 2^{-/-}$neurons.

A number of previous studies have shown that GluR2-lacking AMPARs play important physiological roles in various types of neurons in the CNS (Cull-Candy et al., 2006). Although the majority of AMPARs contain GluR2 subunits, some endogenous 
GluR2-lacking AMPARs do route into synapses during synaptic potentiation (Zhu et al., 2000). In particular, during early postnatal development, in which the expression of GluR2 is relatively low (Zhu et al., 2000; Kolleker et al., 2003), GluR2-lacking AMPARs may mediate a significant portion of synaptic transmission, causing rectified AMPA responses and calcium influx (Zhu et al., 2000; Kumar et al., 2002). In contrast, in juvenile and adult neurons, synaptic GluR2-lacking AMPARs are either removed or replaced by GluR2-containing, calcium-impermeable AMPARs in a GRIP1-dependent manner (Bagal et al., 2005; Bellone and Luscher, 2006; McCormack et al., 2006; Plant et al., 2006). $A L S 2^{-/-}$neurons show increased synaptic/cell surface expression of GluR2-lacking AMPARs, consistent with the findings that GRIP1 plays key roles in replacing synaptic GluR2-lacking AMPARs with GluR2-containing AMPARs and/or in stabilizing GluR2-containing AMPARs at both synaptic and intracellular sites (Dong et al., 1997; Wyszynski et al., 1999; Daw et al., 2000). Furthermore, $A L S 2^{-/-}$neurons display increased susceptibility to glutamate receptor-mediated excitotoxicity, supporting the hypothesis that the increased calcium influx via GluR2-lacking, calcium-permeable AMPARs is one of the major causes of motor neuron degeneration in ALS (Rothstein, 1996; Shaw and Ince, 1997; Kwak and Weiss, 2006). Thus, Our findings reveal a novel function of alsin in AMPAR trafficking and provide a novel molecular pathway linking alsin-deficiency with motor neuron degeneration, which may serves as the therapeutic target for the treatment of ALS2 and related motor neuron diseases.

\section{References}

Bagal AA, Kao JP, Tang CM, Thompson SM (2005) Long-term potentiation of exogenous glutamate responses at single dendritic spines. Proc Natl Acad Sci USA 102:14434-14439.

Bellone C, Luscher C (2006) Cocaine triggered AMPA receptor redistribution is reversed in vivo by mGluR-dependent long-term depression. Nat Neurosci 9:636-641.

Bruijn LI, Miller TM, Cleveland DW (2004) Unraveling the mechanisms involved in motor neuron degeneration in ALS. Annu Rev Neurosci 27:723-749.

Cai H, Reed RR (1999) Cloning and characterization of neuropilin-1interacting protein: a PSD-95/Dlg/ZO-1 domain-containing protein that interacts with the cytoplasmic domain of neuropilin-1. J Neurosci 19:6519-6527.

Cai H, Lin X, Xie C, Laird FM, Lai C, Wen H, Chiang HC, Shim H, Farah MH, Hoke A, Price DL, Wong PC (2005) Loss of ALS2 function is insufficient to trigger motor neuron degeneration in knock-out mice but predisposes neurons to oxidative stress. J Neurosci 25:7567-7574.

Cleveland DW, Rothstein JD (2001) From Charcot to Lou Gehrig: deciphering selective motor neuron death in ALS. Nat Rev Neurosci 2:806-819.

Cull-Candy S, Kelly L, Farrant M (2006) Regulation of $\mathrm{Ca}^{2+}$-permeable AMPA receptors: synaptic plasticity and beyond. Curr Opin Neurobiol 16:288-297.

Daw MI, Chittajallu R, Bortolotto ZA, Dev KK, Duprat F, Henley JM, Collingridge GL, Isaac JT (2000) PDZ proteins interacting with C-terminal GluR2/3 are involved in a PKC-dependent regulation of AMPA receptors at hippocampal synapses. Neuron 28:873-886.

Devon RS, Orban PC, Gerrow K, Barbieri MA, Schwab C, Cao LP, Helm JR, Bissada N, Cruz-Aguado R, Davidson TL, Witmer J, Metzler M, Lam CK, Tetzlaff W, Simpson EM, McCaffery JM, El Husseini AE, Leavitt BR, Hayden MR (2006) Als2-deficient mice exhibit disturbances in endosome trafficking associated with motor behavioral abnormalities. Proc Natl Acad Sci USA 103:9595-9600.

Dong H, O’Brien RJ, Fung ET, Lanahan AA, Worley PF, Huganir RL (1997) GRIP: a synaptic PDZ domain-containing protein that interacts with AMPA receptors. Nature 386:279-284.

Dong H, Zhang P, Song I, Petralia RS, Liao D, Huganir RL (1999) Characterization of the glutamate receptor-interacting proteins GRIP1 and GRIP2. J Neurosci 19:6930-6941.
Eymard-Pierre E, Yamanaka K, Haeussler M, Kress W, Gauthier-Barichard F, Combes P, Cleveland DW, Boespflug-Tanguy O (2006) Novel missense mutation in ALS2 gene results in infantile ascending hereditary spastic paralysis. Ann Neurol 59:976-980.

Hadano S, Hand CK, Osuga H, Yanagisawa Y, Otomo A, Devon RS, Miyamoto N, Showguchi-Miyata J, Okada Y, Singaraja R, Figlewicz DA, Kwiatkowski T, Hosler BA, Sagie T, Skaug J, Nasir J, Brown Jr RH, Scherer SW, Rouleau GA, Hayden MR, et al. (2001) A gene encoding a putative GTPase regulator is mutated in familial amyotrophic lateral sclerosis 2 . Nat Genet 29:166-173.

Hadano S, Benn SC, Kakuta S, Otomo A, Sudo K, Kunita R, SuzukiUtsunomiya K, Mizumura H, Shefner JM, Cox GA, Iwakura Y, Brown Jr $\mathrm{RH}$, Ikeda JE (2006) Mice deficient in the Rab5 guanine nucleotide exchange factor ALS2/alsin exhibit age-dependent neurological deficits and altered endosome trafficking. Hum Mol Genet 15:233-250.

Jacquier A, Buhler E, Schafer MK, Bohl D, Blanchard S, Beclin C, Haase G (2006) Alsin/Racl signaling controls survival and growth of spinal motoneurons. Ann Neurol 60:105-117.

Kolleker A, Zhu JJ, Schupp BJ, Qin Y, Mack V, Borchardt T, Kohr G, Malinow R, Seeburg PH, Osten P (2003) Glutamatergic plasticity by synaptic delivery of GluR-B(long)-containing AMPA receptors. Neuron 40:1199-1212.

Kress JA, Kuhnlein P, Winter P, Ludolph AC, Kassubek J, Muller U, Sperfeld AD (2005) Novel mutation in the ALS2 gene in juvenile amyotrophic lateral sclerosis. Ann Neurol 58:800-803.

Kumar SS, Bacci A, Kharazia V, Huguenard JR (2002) A developmental switch of AMPA receptor subunits in neocortical pyramidal neurons. J Neurosci 22:3005-3015.

Kwak S, Weiss JH (2006) Calcium-permeable AMPA channels in neurodegenerative disease and ischemia. Curr Opin Neurobiol 16:281-287.

Larkum ME, Zhu JJ (2002) Signaling of layer 1 and whisker-evoked $\mathrm{Ca}^{2+}$ and $\mathrm{Na}^{+}$action potentials in distal and terminal dendrites of rat neocortical pyramidal neurons in vitro and in vivo. J Neurosci 22:6991-7005.

Lee SH, Simonetta A, Sheng M (2004) Subunit rules governing the sorting of internalized AMPA receptors in hippocampal neurons. Neuron 43:221-236.

Lin JW, Ju W, Foster K, Lee SH, Ahmadian G, Wyszynski M, Wang YT, Sheng M (2000) Distinct molecular mechanisms and divergent endocytotic pathways of AMPA receptor internalization. Nat Neurosci 3:1282-1290.

Mammen AL, Huganir RL, O’Brien RJ (1997) Redistribution and stabilization of cell surface glutamate receptors during synapse formation. J Neurosci 17:7351-7358.

Maragakis NJ, Jackson M, Ganel R, Rothstein JD (2003) Topiramate protects against motor neuron degeneration in organotypic spinal cord cultures but not in G93A SOD1 transgenic mice. Neurosci Lett 338:107-110.

Martin LJ, Liu Z (2002) DNA damage profiling in motor neurons: a singlecell analysis by comet assay. Neurochem Res 27:1093-1104.

McCormack SG, Stornetta RL, Zhu JJ (2006) Synaptic AMPA receptor exchange maintains bidirectional plasticity. Neuron 50:75-88.

Millecamps S, Gentil BJ, Gros-Louis F, Rouleau G, Julien JP (2005) Alsin is partially associated with centrosome in human cells. Biochim Biophys Acta 1745:84-100.

Otomo A, Hadano S, Okada T, Mizumura H, Kunita R, Nishijima H, Showguchi-Miyata J, Yanagisawa Y, Kohiki E, Suga E, Yasuda M, Osuga H, Nishimoto T, Narumiya S, Ikeda JE (2003) ALS2, a novel guanine nucleotide exchange factor for the small GTPase Rab5, is implicated in endosomal dynamics. Hum Mol Genet 12:1671-1687.

Panzeri C, De Palma C, Martinuzzi A, Daga A, De Polo G, Bresolin N, Miller CC, Tudor EL, Clementi E, Bassi MT (2006) The first ALS2 missense mutation associated with JPLS reveals new aspects of alsin biological function. Brain 129:1710-1719.

Plant K, Pelkey KA, Bortolotto ZA, Morita D, Terashima A, McBain CJ, Collingridge GL, Isaac JT (2006) Transient incorporation of native GluR2-lacking AMPA receptors during hippocampal long-term potentiation. Nat Neurosci 9:602-604.

Portera-Cailliau C, Price DL, Martin LJ (1997) Non-NMDA and NMDA receptor-mediated excitotoxic neuronal deaths in adult brain are morphologically distinct: further evidence for an apoptosis-necrosis continuum. J Comp Neurol 378:88-104.

Qin Y, Zhu Y, Baumgart JP, Strornetta RL, Seidenman K, Mack V, van Aelst L, Zhu JJ (2005) State-dependent Ras signaling and AMPA receptor trafficking. Genes Dev 19:2000-2015.

Reid E, Kloos M, Ashley-Koch A, Hughes L, Bevan S, Svenson IK, Graham FL, Gaskell PC, Dearlove A, Pericak-Vance MA, Rubinsztein DC, Marchuk 
DA (2002) A kinesin heavy chain (KIF5A) mutation in hereditary spastic paraplegia (SPG10). Am J Hum Genet 71:1189-1194.

Rothstein JD (1996) Excitotoxicity hypothesis. Neurology [Suppl] 47:S19-S25.

Rothstein JD, Jin L, Dykes-Hoberg M, Kuncl RW (1993) Chronic inhibition of glutamate uptake produces a model of slow neurotoxicity. Proc Natl Acad Sci USA 90:6591-6595.

Setou M, Seog DH, Tanaka Y, Kanai Y, Takei Y, Kawagishi M, Hirokawa N (2002) Glutamate-receptor-interacting protein GRIP1 directly steers kinesin to dendrites. Nature 417:83-87.

Shaw PJ, Ince PG (1997) Glutamate, excitotoxicity and amyotrophic lateral sclerosis. J Neurol 244 [Suppl 2]:S3-S14.

Shi SH, Hayashi Y, Petralia RS, Zaman SH, Wenthold RJ, Svoboda K, Malinow R (1999) Rapid spine delivery and redistribution of AMPA receptors after synaptic NMDA receptor activation. Science 284:1811-1816.

Song I, Huganir RL (2002) Regulation of AMPA receptors during synaptic plasticity. Trends Neurosci 25:578-588.

Topp JD, Gray NW, Gerard RD, Horazdovsky BF (2004) Alsin is a Rab5 and Racl guanine nucleotide exchange factor. J Biol Chem 279:24612-24623.

Toth K, McBain CJ (1998) Afferent-specific innervation of two distinct AMPA receptor subtypes on single hippocampal interneurons. Nat Neurosci 1:572-578.

Tudor EL, Perkinton MS, Schmidt A, Ackerley S, Brownlees J, Jacobsen NJ, Byers HL, Ward M, Hall A, Leigh PN, Shaw CE, McLoughlin DM, Miller CC (2005) ALS2/Alsin regulates Rac-PAK signaling and neurite outgrowth. J Biol Chem 280:34735-34740.
Wyszynski M, Valtschanoff JG, Naisbitt S, Dunah AW, Kim E, Standaert DG, Weinberg R, Sheng M (1999) Association of AMPA receptors with a subset of glutamate receptor-interacting protein in vivo. J Neurosci 19:6528-6537.

Yamanaka K, Vande VC, Eymard-Pierre E, Bertini E, Boespflug-Tanguy O, Cleveland DW (2003) Unstable mutants in the peripheral endosomal membrane component ALS2 cause early-onset motor neuron disease. Proc Natl Acad Sci USA 100:16041-16046.

Yamanaka K, Miller TM, McAlonis-Downes M, Chun SJ, Cleveland DW (2006) Progressive spinal axonal degeneration and slowness in ALS2deficient mice. Ann Neurol 60:95-104.

Yang Y, Hentati A, Deng HX, Dabbagh O, Sasaki T, Hirano M, Hung WY, Ouahchi K, Yan J, Azim AC, Cole N, Gascon G, Yagmour A, Ben Hamida M, Pericak-Vance M, Hentati F, Siddique T (2001) The gene encoding alsin, a protein with three guanine-nucleotide exchange factor domains, is mutated in a form of recessive amyotrophic lateral sclerosis. Nat Genet 29:160-165.

Zamanillo D, Sprengel R, Hvalby O, Jensen V, Burnashev N, Rozov A, Kaiser KM, Koster HJ, Borchardt T, Worley P, Lubke J, Frotscher M, Kelly PH, Sommer B, Andersen P, Seeburg PH, Sakmann B (1999) Importance of AMPA receptors for hippocampal synaptic plasticity but not for spatial learning. Science 284:1805-1811.

Zhu JJ, Esteban JA, Hayashi Y, Malinow R (2000) Postnatal synaptic potentiation: delivery of GluR4-containing AMPA receptors by spontaneous activity. Nat Neurosci 3:1098-1106. 